Original Research Article

\title{
Patterns of drug use and drug dispensing in dermatology outpatient prescriptions in a tertiary care teaching hospital
}

\author{
Aravinda Kumar*
}

Department of Pharmacology, Pondicherry Institute of Medical Sciences,

Ganapathychettikulam,

Puducherry, India

Received: 23 June 2018

Accepted: 29 June 2018

*Correspondence to:

Dr. Aravinda Kumar,

Email: aravindkumar007@

gmail.com

Copyright: (C) the author(s), publisher and licensee Medip Academy. This is an openaccess article distributed under the terms of the Creative Commons Attribution NonCommercial License, which permits unrestricted noncommercial use, distribution, and reproduction in any medium, provided the original work is properly cited.

\begin{abstract}
Background: Periodic assessment of drug prescribing and dispensing pattern in a hospital facility shall play a major role in avoiding the inappropriate use of drugs which leads to potential hazards and expenses for the patients.

Methods: The objective of the study was to analyse the patterns of drug use and dispensing in dermatology outpatient prescriptions from a tertiary care teaching hospital in south India. Data were collected over a period of one month from patients attending dermatology outpatient department by scrutinizing 100 prescriptions and analyzed using WHO formulated "core drug use indicators" like the format, prescribing pattern and rationality of prescriptions.

Results: The total number of drugs prescribed in 100 prescriptions was 233 i.e. on average 2.33 drugs were prescribed per patient. The patient's name and age were mentioned in all the prescriptions while diagnosis, dose, route of administration, dosage form, duration of therapy and prescriber's identity was written in $43.29 \%, 68.04 \%, 69.07 \%, 100 \%, 49.48 \%$ and $63.91 \%$ prescriptions respectively. Out of all drugs, $42.91 \%$ were generic drugs and $57.08 \%$ were from National Essential Drug List of India. Steroids (18.02\%) were the most common group of drugs used, followed by keratolytics and emollients (15.87\%). Most of the drugs were given by topical route $(47.63 \%)$.

Conclusions: A prescription by a doctor is a reflection of physicians' attitude towards the disease and the role of drug in its treatment. It also provides an insight into the nature of health care at that facility. Interventions to rectify over proper prescription format and prescription of generic drugs are necessary to further improve rational drug use in this facility.
\end{abstract}

Keywords: Dermatology, Prescription pattern, Rationale drug use, WHO core drug use indicators

\section{INTRODUCTION}

Appropriate use of medicines is essential to provide better health and medical care to patients and the community. World Health Organization (WHO) defines rational use of medicines as "patients receive medications appropriate to their clinical needs, in doses that meet their own individual requirements, for an adequate period of time, and at the lowest cost to them and their community". ${ }^{1}$ The fundamental steps to limit the irrational use of medicines is to identify the type, amount and reasons of irrational use of medicines. The WHO in collaboration with the International Network of Rational Use of Drugs (INRUD) developed a set of indicators to measure the performance of healthcare facilities related to rationale utilization of drugs. $^{2}$

A prescription is a document between the physician and the patient consisting a medication for a person's illness at a particular time. It focuses on therapeutic proficiency of the physician with instructions for palliation or restoration of the patient's health. ${ }^{3}$ In order to ensure a physician's skill in selection of an appropriate cost effective choice of 
treatment to any patient, a continuous assessment of prescription is required.

Drug utilization studies deals with prescription and use of drugs in a society with special emphasis on the resulting medical and social consequences. Periodic medical audit had set the standards for medical treatment at all levels of the health care delivery system and assess the quality of care through performance review in everyday clinical practice. WHO-India program on the rational use of drugs aims at promoting rational prescribing through a multipronged strategy, which includes intervention to correct drug use problems, adoption of essential drug list, development of standard treatment guidelines, determining and restricting irrational prescribing. Various factors could influence the prescribing behavior of the clinicians and it is difficult to change the behavior without understanding the reason behind. ${ }^{4}$ Drug utilization studies conducted recently in dermatology across India have reported issues of high prescribing of branded drugs, low adoption of essential drug and polypharmacy, thus creating concern regarding the rational use of drugs in dermatology specialty.

The present study was planned with an objective to analyse the patterns of drug use and dispensing in dermatology outpatient prescriptions from a tertiary care teaching hospital in Puducherry.

\section{METHODS}

The present study was a prospective, cross-sectional, observational study conducted over a period of two months. It was conducted in the pharmacy of a tertiary care teaching hospital in Puducherry. Duplicate copies of the hundred (100) written prescriptions from the department of dermatology were collected from the pharmacy counter. The data obtained from them were analyzed using WHO formulated "core drug use indicators" which comprised of prescribing indicators.

Prescribing indicators included correct format, prescribing pattern and rationality of prescriptions. Format of the prescription was checked for name, age, gender, hospital number and diagnosis of the patient, generic name in upper case with correct dose, frequency, duration and route of administration of the drug and doctor's profile with signature. Prescribing pattern was assessed by analyzing the most common drugs prescribed under various categories for different dermatological ailments. Rationality was assessed by analyzing the appropriateness and the number of the drugs prescribed per prescription for various ailments from essential drug list.

The data was further analyzed for the most commonly prescribed drug groups, percentage of: oral drugs, topical preparations (combination/ single preparations), injectable, drug dispensed from pharmacy of the hospital, prescriptions with combination of topical and oral agents, and various cleaning agents.

\section{Statistical analysis}

The collected prescription data was analyzed using descriptive statistics. Values were expressed as actual numbers and percentage.

\section{RESULTS}

A total number of 100 prescriptions from patients attending the dermatology OPD were included for analysis. The findings pertaining to prescription format are shown in Table 1 which shows that patient's name, age, gender and hospital number were mentioned in almost all the prescriptions. The diagnosis of the patient was seen only in $43.29 \%$ prescriptions. The dose, strength and route of administration was seen in $69 \%$ prescriptions. The frequency and dosage form were seen in $80 \%$ and $100 \%$ prescriptions respectively. Prescriber's identity was legible in only $63.9 \%$ prescriptions, but none had the registration number of the prescriber because it is a hospital OPD and not a private clinic, so writing the registration number is not mandatory.

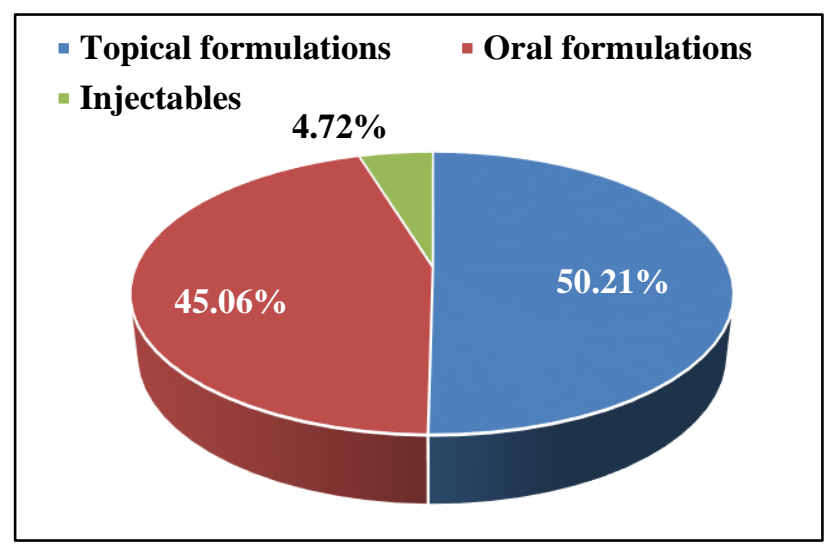

Figure 1: Percentage distribution of dermatological dosage formulations used.

Table 1: Prescription indicators.

\begin{tabular}{|ll|}
\hline Contents of the prescription & $\%$ \\
\hline Name of the patient & $100 \%$ \\
\hline Age of the patient & $97.94 \%$ \\
\hline Gender of the patient & $98.97 \%$ \\
\hline Hospital number of the patient & $98.97 \%$ \\
\hline Department name & $94.84 \%$ \\
\hline Doctor's profile & $63.91 \%$ \\
\hline Doctor's signature & $97.94 \%$ \\
\hline Diagnosis & $43.29 \%$ \\
\hline Dose/Strength of drug & $68.04 \%$ \\
\hline Route of administration & $69.07 \%$ \\
\hline Frequency & $81.44 \%$ \\
\hline Dosage form & $100 \%$ \\
\hline
\end{tabular}

These patients were prescribed 233 drugs, with an average of 2.33 drugs per prescription. Out of all the drugs, $57.08 \%$ drugs were from the National Essential Drug List of India. 
Only $42.91 \%$ drugs were prescribed under their respective generic names. The total number of drugs to be dispensed by the pharmacist is mentioned in $74 \%$ of the prescriptions and duration of treatment was mentioned only in $49 \%$ of the prescriptions (Table 2).

\section{Table 2: Drug usage (Prescribing indicators).}

\begin{tabular}{|ll|}
\hline Total number of drugs prescribed & $\mathbf{2 3 3}$ \\
\hline Average number of drugs per patient & 2.33 \\
\hline Total number of drugs to be dispensed & $74.22 \%$ \\
\hline Prescriptions with generic drugs & $42.91 \%$ \\
\hline $\begin{array}{l}\text { Prescriptions with drugs from Essential } \\
\text { Drug List }\end{array}$ & $57.08 \%$ \\
\hline Duration of treatment mentioned & $49.48 \%$ \\
\hline
\end{tabular}

Table 3: Percentage distribution of therapeutic categories of drugs used.

\begin{tabular}{|lll|}
\hline Type of drugs & $\begin{array}{l}\text { Number } \\
\text { of drugs } \\
\text { prescribed }\end{array}$ & $\%$ \\
\hline Antihistamines & 33 & $13.98 \%$ \\
\hline Antifungals & 30 & $12.71 \%$ \\
\hline Antibiotics & 27 & $11.44 \%$ \\
\hline Antivirals & 2 & $0.84 \%$ \\
\hline Antiseptics/Ectoparasitics & 5 & $2.11 \%$ \\
\hline Steroids and combinations & 42 & $18.02 \%$ \\
\hline $\begin{array}{l}\text { Keratolytics/Emolients/ } \\
\text { Antipruritics }\end{array}$ & 37 & $15.67 \%$ \\
\hline Vitamins & 10 & $4.23 \%$ \\
\hline Antidandruff preparations & 2 & $0.84 \%$ \\
\hline Miscellaneous & 48 & $20.33 \%$ \\
\hline
\end{tabular}

Table 4: Percentage distribution of most commonly used drugs under various therapeutic categories of drugs used.

\begin{tabular}{|ll|}
\hline Category of drug & $\begin{array}{l}\text { Major therapeutic agents most } \\
\text { commonly prescribed (\%) }\end{array}$ \\
\hline Antihistamines & $\begin{array}{l}\text { Levocetrizine (O) - 60.6\% } \\
\text { Hydroxyzine (O) - 30.3\% }\end{array}$ \\
\hline Antifungals & $\begin{array}{l}\text { Clotrimazole (T) - 25\% } \\
\text { Fluconazole (O) - 40\% }\end{array}$ \\
\hline Antibiotics & $\begin{array}{l}\text { Fusidic acid (T) - 22.2\% } \\
\text { Cefadroxil (O) - 18.5\% }\end{array}$ \\
\hline $\begin{array}{l}\text { Steroids and } \\
\text { combinations }\end{array}$ & $\begin{array}{l}\text { Clobetasol propionate (T) - } \\
\text { Betamethasone (T) - 28.57\% } \\
\text { Prednisolone (O) - 14.28\% }\end{array}$ \\
\hline $\begin{array}{l}\text { Keratolytics and } \\
\text { emolients }\end{array}$ & Liquid paraffin (T) - 43.24\% \\
\hline $\begin{array}{l}\text { (O) denotes oral formulation and (T) denotes topical } \\
\text { formulation }\end{array}$ & \\
\hline
\end{tabular}

Among the drugs prescribed, corticosteroids were the most commonly used $(18.02 \%)$ followed by keratolytics and emollients (15.67\%) and antihistamines (13.98\%) (Table $3)$.

Among the corticosteroids prescribed, Clobetasol propionate was the most commonly prescribed drug (38.09\%) via topical route of administration followed by Betamethasone (28.57\%) and Prednisolone (14.28\%) via topical and oral routes of administration respectively. Among the keratolytics and emollients prescribed, liquid paraffin was the most commonly prescribed drug (43.24\%) via topical route of administration. Among the antihistamines prescribed, Levocetrizine (60.6\%) and Hydroxyzine (30.3\%) were the most commonly prescribed drug via oral route of administration. Fusidic acid (22.2\%) and Cefadroxil (18.5\%) were the most common antibiotics prescribed. Clotrimazole (25\%) and Fluconazole (40\%) were the most common antifungals prescribed (Table 4). Miscellaneous groups of drugs included mainly analgesics, gastro protective agents and vitamins for nondermatological conditions.

\section{DISCUSSION}

A large number of studies on drug utilization and prescription patterns have been carried out in developing countries.

A large number of studies on drug utilization and prescription patterns have been carried out in developed and developing countries. Differences do exist in patterns of drug consumption and hence results of studies conducted in developed countries cannot be applied to developing countries. Though such studies have been done in India at both hospital and community level, yet they are not adequate enough to depict a clear picture of drug use. ${ }^{5}$ Average number of drugs is an important index of prescription analysis and in the present study, it was 2.33 . Our findings were in conformity with some of the other hospital studies done in India which showed 2-3 drugs per prescription. $^{5-7}$ It is evident that polypharmacy is not practiced in this facility. It is preferable to keep the average number of drugs per prescription as low as possible since higher figures always lead to increased risk of drug interactions, adverse drug reactions, poor medication compliance and eventually increased cost of prescription. The dose and dosage schedule were mentioned in almost all the prescriptions and this can avoid an increase in the overall cost of treatment due to inappropriate use of drugs by the patient. The most commonly prescribed drug group in this study was corticosteroids followed by keratolytics and emollients and antihistamines. Analysis of the prescription data revealed that inflammatory disorders were the most common diagnosis that explains the greater use of corticosteroids. Among the total number of drugs prescribed, most of them were prescribed by the topical route followed by oral and injectable routes. Consistent data was reported by other studies. ${ }^{7,8}$ The reason for high percentage of topical drugs being prescribed is that topical route has minimum side effects hence is the preferred route of administration in dermatology. Prescribing under a 
generic name is considered economical and rational but only few patients in the present study were prescribed generic drugs $(42.9 \%)$ as compared to proprietary drugs $(57.1 \%)$. Our results were consistent with other studies done by Maini $\mathrm{R}$ et al and Narwane SP et al. ${ }^{8,9}$ Poor prescribing of generic drugs can be because of concern about their quality.

Drugs from Essential Drug List (EDL) constituted about $57.08 \%$ in this study, while it was reported as $95.78 \%$ by Biswas et al, and $51 \%$ by Georgekutty et al. ${ }^{10,11}$ Use of essential drug list or hospital formulary based on National essential drug list helpful satisfying majority of health need of population in geographical area of tertiary care hospital which was satisfactory in this study. As the institution is a private tertiary care hospital that has advanced treatment available, the newer drugs have also been used which are not yet included in the EDL. Also as the institution is a private medical college so as such there is no compulsion to prescribe from the EDL but where ever possible, the due consideration has been given to prescribe from EDL.

\section{CONCLUSION}

A prescription by a doctor is a reflection of physicians' attitude towards the disease and the role of drug in its treatment. It also provides an insight into the nature of health care at that facility. Interventions to rectify over proper prescription format and prescription of generic drugs are necessary to further improve rational drug use in this facility.

\section{ACKNOWLEDGEMENTS}

Authors would like to express their humble gratitude to the hospital pharmacy for sharing the prescription copies and the Institution for their moral support to conduct the study.

Funding: No funding sources

Conflict of interest: None declared

Ethical approval: Not required

\section{REFERENCES}

1. Atif M, Sarwar MR, Azeem M, Naz M, Amir S, Nazir $\mathrm{K}$. Assessment of core drug use indicators using WHO/INRUD methodology at primary healthcare centers in Bahawalpur, Pakistan. BMC Health Serv Res. 2016;16:684.

2. World Health Organization. How to investigate drug use in health facilities: selected drug use indicators; 1993. Available at: http://apps.who.int/medicinedocs/en/d/Js2289e/. Accessed 18 Oct 2015.

3. Tikoo D, Chopra SC, Kaushal S, Dogra A. Evaluation of Drug Use Pattern in Dermatology as a Tool to Promote Rational Prescribing. 2011;13(3):4.

4. Shewade DG, Pradhan SC. Auditing of prescriptions in a government teaching hospital and four retail medical stores in Pondicherry. Indian J Pharmacol. 1998;30:408-10.

5. Minocha KB, Bajaj S, Gupta K. A clinic pharmacological study of outpatient prescribing pattern of dermatological drugs in an Indian tertiary hospital. Indian J Pharmacol. 2000;32:384-85.

6. Badar VA, Shrivastava MP, Badwaik RT. Surveillance of drug prescribing trends in skin OPD of IGMC. Indian J Pharmacol. 2002;34:150.

7. Nithyanandan NA, Jhaj R, Balakrishnan S. Prescription audit in a tertiary care center in rural Pondicherry. Proceedings Pharmacology today progressing academia-industry interactions New Delhi. 2003:256.

8. Maini R, Verma KK, Biswas NR, Agrawal SS. Drug utilization study in dermatology in a tertiary hospital in Delhi. Ind J of Physiolo and Pharmacol. 2002 Jan 25;46(1):107-10.

9. Narwane SP, Patel TC. Shetty YC, Chikhalkar SB. Drug Utilization and Cost Analysis for Common Skin Diseases in Dermatology OPD of an Indian Tertiary Care Hospital - A Prescription Survey. Bri J of Pharmaceuti Resear. 2011;1(1):9-18.

10. Biswas NR, Biswas RS, Pal PS, Jain SK, Malhotra SP, Gupta AS, et al. Patterns of prescriptions and drug use in two tertiary hospitals in Delhi. Indian Journal of Physiology and Pharmacology. 2000 Jan 5;44(1):10912.

11. Georgekutty KV, Sambasivam N, Nagarajan M. A study on drug prescribing pattern in Madurai city. Indian J Pharmacol. 2002;34:361-2.

Cite this article as: Kumar A. Patterns of drug use and drug dispensing in dermatology outpatient prescriptions in a tertiary care teaching hospital. Int $\mathbf{J}$ Basic Clin Pharmacol 2018;7:1494-7. 